\title{
Effects of different drying methods on the physicochemical properties of powders obtained from high-oleic palm oil nanoemulsions
}

Hernández-Carrión, M.; Moyano-Molano, M.; Ricaurte, L.; Moreno, F.L.; Quintanilla-Carvajal, M.X.*

Faculty of Engineering. Universidad de La Sabana, Bogotá, Colombia

*E-mail of the corresponding author: maria.quintanilla1@unisabana.edu.co

\begin{abstract}
Nanoencapsulation is an efficient process to incorporate high nutritional oils, such as high oleic palm oil (HOPO). Several drying technologies can be applied for obtaining HOPO powders. The aim of this work was to study the effect of two different drying methods (spray-drying, SP and freeze-drying, $F D$ ) on some physical properties and microstructure of powders obtained from HOPO nanoemulsions. Results showed that FD powders presented lower $a_{w}$ and bulk density, and higher dissolution rate than SD powders. Results suggest that SD could be a more economical alternative to FD in order to obtain HOPO powders with low moisture and $a_{w}$.
\end{abstract}

Keywords: freeze-drying; high oleic palm oil; nanoemulsion; spray drying. 


\section{Introduction}

Nanoencapsulation is an efficient process to encapsulate bioactive compounds and thus allows the incorporation of high nutritional oils, such as high oleic palm oil (HOPO) [1]. Nanoencapsulation often begins with the production of nanoemulsion [2]. One of the techniques used for obtaining nanoemulsions is microfluidisation; it has been widely used and represents a highly efficient method for producing nanoemulsions containing smallsized droplets (100-500 nm) [3].

Several drying technologies can be applied for obtaining HOPO powders such as freezedrying and spray-drying. The final product obtained from these methods may differ in physicochemical properties and microstructures [4]. Spray drying is widely used in commercial production of milk powders, fruits and vegetables [5]. This method has several advantages such as rapid drying, large throughput and continuous operation. During the drying process, the feed solution is sprayed in droplets in a stream of hot air [6]. The liquid droplets are dried in seconds as a result of the highly efficient heat and mass transfers [7]. The finished product can be made in the form of powder, granules or agglomerates [8]. Freeze drying, also known as lyophilisation, is a drying process in which the food is first frozen then dried by direct sublimation of the ice under reduced pressure. To carry out a successful freeze drying operation, the pressure in the drying chamber must be maintained at an absolute pressure of at least $620 \mathrm{~Pa}$ [7]. Freeze drying is generally considered as the best method for production of high quality dried products [9]. But, it suffers from high production costs, high energy consumptions, and low throughputs [10].

So, the aim of this work was to study the effect of two different drying methods, spray drying and freeze drying on some physical properties and microstructure of powders obtained from nanoemulsions of HOPO.

\section{Materials and Methods}

\subsection{Materials}

HOPO (Fedepalma, Bogotá, Colombia); whey powder was bought in a local market (Bogotá, Colombia); soy lecithin (Bellchem International, Medellín, Colombia); and native corn starch (Cimpa SAS, Bogotá, Colombia).

\subsection{Nanoemulsion preparation}

The coarse emulsions were homogenised in an mixer (Imusa, Bogotá, Colombia), incorporating whey powder $(29.76 \%$, w/w), followed by the sequential addition of native corn starch $(0.24 \%, \mathrm{w} / \mathrm{w})$, and HOPO $(14 \%, \mathrm{w} / \mathrm{w})$ to the distilled water over $2 \mathrm{~min}$. Subsequently, such emulsions were processed to obtain the nanoemulsions. The soy lecithin 
concentration was held constant at $10 \% \mathrm{w} / \mathrm{w}$ with respect to the HOPO concentration (1.4\%, w/w). The nanoemulsions were obtained following the methodology of QuintanillaCarvajal et al., [11] with some modifications at 20,000 psi pressure for 2 cycles.

\subsection{Drying technologies}

Two different drying methods were applied: spray-drying (SP), and freeze-drying (FD).

\subsubsection{Spray drying}

HOPO powders produced by SD (SDP) were obtained in a pilot scale spray dryer (Niro MM-PSR, GEA Process Engineering A/S, Denmark) using two-fluid nozzle as atomisation device at 1 bar of pressure. The nanoemulsions were fed into the atomiser by a peristaltic pump (Watson-Marlow, United Kindom). The inlet and outlet temperatures of the drying air were 190 and $90^{\circ} \mathrm{C}$, respectively.

\subsubsection{Freeze drying}

HOPO powders produced by FD (FDP) were obtained in a pilot scale freeze dryer (Labconco, USA). The nanoemulsion was poured into a stainless pan to form a layer of $10 \mathrm{~mm}$. The samples were frozen at $-40^{\circ} \mathrm{C}$ with a cooling rate of $0.5^{\circ} \mathrm{C} / \mathrm{min}$ for $16.5 \mathrm{~h}$. Then, the samples were sublimated at a temperature of $-20^{\circ} \mathrm{C}$ for $12 \mathrm{~h}$ and a desorption temperature of $20^{\circ} \mathrm{C}$ for $24 \mathrm{~h}$. The pressure on the chamber was 0.018 mbar. Then, an analytical batch mill (A 11 M Basic, IKA, USA) at 28,000 rpm during $10 \mathrm{~s}$ was used for the obtention of the FDP.

\subsection{Physical properties of the powders}

\subsubsection{Moisture}

The moisture content of the powders was measured from $0.3 \mathrm{~g}$ of sample employing an EM 120-HR moisture analyser (Precisa Gravimetrics AG, Dietikon, Switzerland). Measurements were performed in triplicate.

\subsubsection{Water activity $\left(a_{w}\right)$}

The water activity of the powders was measured using an AquaLab Series 4 aw meter (Decagon Devices, Inc., Pullman, WA) after the samples were stabilised at $25{ }^{\circ} \mathrm{C}$ for 30 min. The measurements were performed in triplicate.

\subsubsection{Dissolution rate $(D R)$}

The dissolution rate was carried out by adding $2 \mathrm{~g}$ of the powders into $50 \mathrm{~mL}$ of distilled water [12]. The mixture was agitated in a $100 \mathrm{~mL}$ low form glass beaker with a magnetic stirrer (Heidolph, Schwabach, Germany) at $900 \mathrm{rpm}$. The time (s) required for the material to completely dissolve was recorded. The measurements were performed in triplicate. 


\subsubsection{Bulk density (BD)}

The bulk density of the powders was measured by weighing $2 \mathrm{~g}$ of sample and placing it in a $10 \mathrm{~mL}$ graduated test tube. The test tube was tapped by hand and the bulk density was calculated as the ratio between the mass (g) of powder contained in the test tube and the volume occupied [13]. The measurements were performed in triplicate.

\subsection{Microstructure}

For the analysis of the structure of the HOPO powders a scanning electron microscope (Phenom Pro, Cecoltec Ltda, Bogotá, Colombia) was used. Samples were placed on the SEM slides with the aid of colloidal silver. An acceleration voltage of $5 \mathrm{kV}$ and two different magnifications of 1000x and 4000x were used.

\subsection{Statistical analysis}

Data were subjected to variance analysis (ANOVA), using the least significant difference (LSD) test with a 95\% ( $p<0.05$ ) confidence interval to compare the test averages (Statgraphics Plus 5.1, Manugistics, Inc., Rockville, MD, USA).

\section{Results and Discussion}

\subsection{Physical properties}

Physical properties of the HOPO powders obtained using two different drying methods, SD and FD are shown in Table 1 . Results showed that no significant differences $(p>0.05)$ were obtained between the moisture of FDP compared to that obtained in SDP (Table 1). Although no significant differences in moisture content were found, both methods are totally adequate for emulsion drying because in industrial food, moisture values under 15\% prevent microorganism growth, increase structural stability and retards deterioration reactions as sugar crystallization, non enzymatic browning and aroma losses [14].

Table 1. Physicochemical properties of HOPO powders obtained by two different drying methods

\begin{tabular}{ccccc}
\hline Drying method & Moisture (\%) & $\mathbf{a}_{\mathrm{w}}$ & DR (s) & BD (g/mL) \\
\hline SD & $2.43^{\mathrm{a}}(0.05)$ & $0.1621^{\mathrm{a}}(<0.01)$ & $83.00^{\mathrm{a}}(9.9)$ & $0.6366^{\mathrm{a}}(0.01)$ \\
FD & $2.31^{\mathrm{a}}(0.01)$ & $0.0701^{\mathrm{b}}(0.01)$ & $146.00^{\mathrm{b}}(5.7)$ & $0.5154^{\mathrm{b}}(<0.01)$ \\
\hline
\end{tabular}

DR: dissolution rate; BD: bulk density.

The values in parenthesis are the standard deviations.

${ }^{a b c}$ In the same column, means without the same letter reveal significant differences $(p<0.05)$ according to the LSD multiple range test. 
On the other hand, FDP presented lower $\mathrm{a}_{\mathrm{w}}$ values $(p<0.05)$ than SDP (Table 1$)$. This may be caused because the high vacuum used. The high vacuum gradient can affect the water transfer rate within the molecular structure, resulting in a lower residual $a_{w}$ in the final product [15]. In the SD method, increasing the temperature of the inlet air, increases the temperature gradient between the air flow and the emulsion, which results in the increase of heat transfer and, therefore, the rate of evaporated water [16]. In addition, the rapid drying in the SD method produces a homogeneous particle size that helps a faster contraction of the particles after water evaporation, generating a minimum amount of available water [17]. It is known that with an $\mathrm{a}_{\mathrm{w}}$ below 0.3 , the water present is not enough to behave like a solvent, which decreases the mobility of the products available for degradation reactions and microbial growth [18]. In this sense, both drying technologies allow obtaining stable products from the point of view of water activity.

In relation to bulk densisty (BD), FDP presented lower BD values $(p<0.05)$ than SDP (Table 1). Baeghbali et al, [19] when studying the effect of different drying methods on the physical properties of pomegranate juice obtained that spray dried samples had higher BD compared to refractance window dried samples because of the fine structure of the spray dried sample. It is known that BD is directly related to the moisture content of the powders. With less moisture content, less water will be present in the structure, which allows more empty spaces between the particles and the interior of these. In this way, increasing the porosity, will increase the surface area per unit volume, and finally will decrease the BD [20]. This fact would explain the higher BD obtained in spray dried HOPO powders due to its high moisture content compared to that obtained by FD.

Finally, FDP presented higher DR values $(p<0.05)$ than SDP (Table 1$)$. Similar results were obtained by Caparino et al., [4] when studying the effect of different drying methods on the physical properties and microstructure of mango powder. These authors obtained higher solubility (lower DR) on the spray dried mango powder compared to freeze dried product. They established that the atomization of mango puree during spray drying could contribute to solubility of spray-dried product. This fact would explain the higher solubility obtained in spray dried HOPO powders compared to that obtained by FD.

\subsection{Microstructure}

Scanning electron micrographs of HOPO powders obtained by different drying processes are shown in Fig.1. Spray-dried HOPO powders (Fig. 1A and 1C) has spherical or oval shape and smooth surface particles due to effect of spray-drying condition, which was maintained at inlet temperature of $190^{\circ} \mathrm{C}$ during drying. On the other hand, freeze dried HOPO powders (Fig. 1B and 1D) showed a skeletal-like structure. Similar results were obtained by Caparino et al [4] when studying the effect of different drying methods on the 
physical properties and microstructure of mango powder. These authors obtained a more spherical shape, and more smooth and porous surface on spray dried mango powder compared to freeze dried product. The smooth spherical-shaped HOPO powder could contributed to its high solubility and BD compared to the freeze drying method.
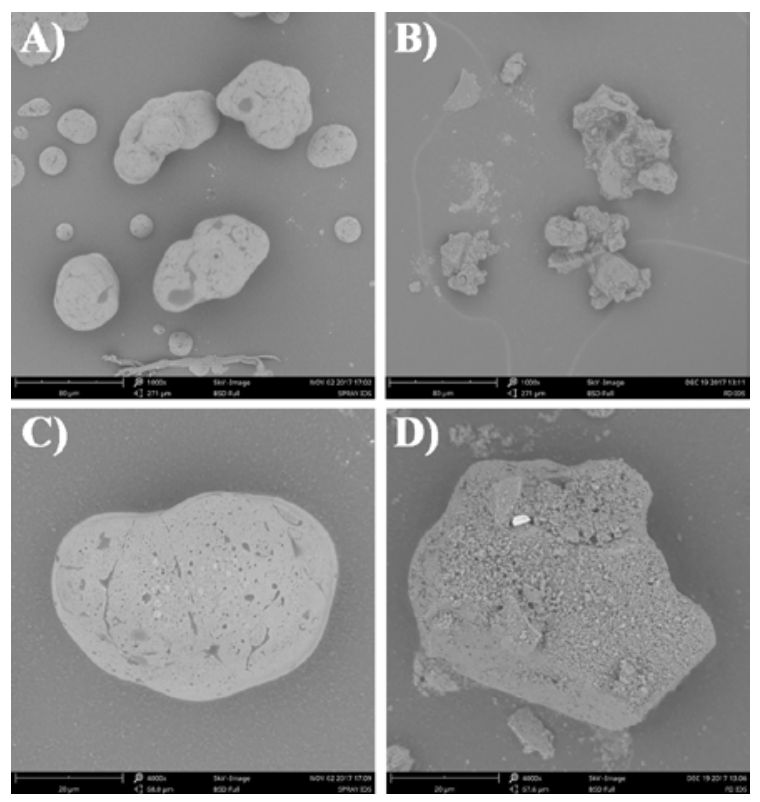

Fig. 1 Scanning electron microscopy micrographs for powders of HOPO nanoemulsions obtained using spray drying $(A, C)$ and freeze drying $(B, D)$. Magnification: 1000x $(A, B), 4000 x(C, D)$.

\section{Conclusions}

Results showed that of the four response variables analysed, three were significantly affected by the drying method applied $(p<0.05)$. No significant differences $(p>0.05)$ were obtained between the moisture of FD powders compared to those obtained by SD. Moreover, FD powders presented lower activity water and BD, and higher DR than SD powders. These important changes in the physicochemical properties of the powders of HOPO could be related to structural modifications observed. So, results suggest that SD could be a more economical alternative to FD in order to obtain HOPO powders with low moisture and activity water and higher solubility. 


\section{Acknowledgements}

The authors wish to acknowledge to Banco de Desarrollo de América Latina (CAF) for the support to this research and to the Universidad de La Sabana for its help in this investigation through the funding of the ING-170-2016 project. Moreover, the authors thank to Cenipalma (Colombia) for kindly supplying the High Oleic Palm Oil used in this study and to Alexandra Mondragón Serna, Leader of the project of Health and Nutrition of Cenipalma.

\section{References}

[1] Ricaurte, L., M.d.J. Perea-Flores, A. Martinez, and M.X. Quintanilla-Carvajal. Production of high-oleic palm oil nanoemulsions by high-shear homogenization (microfluidization). Innov. Food Sci. Emerg. Technol., 2016. 35, 75-85.

[2] Pan, H., L. Yu, J. Xu, and D. Sun. Preparation of highly stable concentrated W/O nanoemulsions by PIC method at elevated temperature. Colloids and Surfaces A: Physicochemical and Engineering Aspects, 2014. 447, 97-102.

[3] Lee, L. and I.T. Norton. Comparing droplet breakup for a high-pressure valve homogeniser and a Microfluidizer for the potential production of food-grade nanoemulsions. J. Food Eng., 2013. 114(2), 158-163.

[4] Caparino, O.A., J. Tang, C.I. Nindo, S.S. Sablani, J.R. Powers, and J.K. Fellman. Effect of drying methods on the physical properties and microstructures of mango (Philippine ‘Carabao’ var.) powder. J. Food Eng., 2012. 111(1), 135-148.

[5] Kha, T.C., M.H. Nguyen, and P.D. Roach. Effects of spray drying conditions on the physicochemical and antioxidant properties of the Gac (Momordica cochinchinensis) fruit aril powder. Journal of Food Engineering, 2010. 98(3), 385-392.

[6] Saravacos, G.D. and A.E. Kostaropoulos. Handbook of Food Processing Equipment; Springer International Publishing: 2002.

[7] Toledo, R.T. Fundamentals of Food Process Engineering; Springer US: 2007.

[8] Nindo, C.I. and J. Tang. Refractance Window Dehydration Technology: A Novel Contact Drying Method. Drying Technology, 2007. 25(1), 37-48.

[9] Ratti, C. Hot air and freeze-drying of high-value foods: a review. Journal of Food Engineering, 2001. 49(4), 311-319.

[10] Caparino, O. Characteristics and quality of freeze-dried mango powder pre-frozen at different temperatures. Philippine Agricultural Scientist Journal, 2000. 83(4), 338343.

[11] Quintanilla-Carvajal, M.X., H. Hernández-Sánchez, L. Alamilla-Beltrán, G. ZepedaVallejo, M.E. Jaramillo-Flores, M. de Jesús Perea-Flores, A. Jimenez-Aparicio, and G.F. Gutiérrez-López. Effects of microfluidisation process on the amounts and distribution of encapsulated and non-encapsulated $\alpha$-tocopherol microcapsules obtained by spray drying. Food Research International, 2014. 63, Part A, 2-8. 
[12] El-Tinay, A.H. and I.A. Ismail. Effects of some additives and processes on the characteristics of agglomerated and granulated spray-dried roselle powder. Acta Alimentaria, 1985. 14(3), 283-295.

[13] Ferrari, C.C., S.P. Marconi Germer, I.D. Alvim, and J.M. de Aguirre. Storage stability of spray-dried blackberry powder produced with maltodextrin or gum arabic. Drying Technology, 2013. 31(4), 470-478.

[14] Tontul, I. and A. Topuz. Effects of different drying methods on the physicochemical properties of pomegranate leather (pestil). LWT - Food Science and Technology, 2017. 80, 294-303.

[15] Moayyedi, M., M.H. Eskandari, A.H.E. Rad, E. Ziaee, M.H.H. Khodaparast, and M.T. Golmakani. Effect of drying methods (electrospraying, freeze drying and spray drying) on survival and viability of microencapsulated Lactobacillus rhamnosus ATCC 7469. Journal of Functional Foods, 2018. 40, 391-399.

[16] Hu, L., J. Zhang, Q. Hu, N. Gao, S. Wang, Y. Sun, and X. Yang. Microencapsulation of brucea javanica oil: Characterization, stability and optimization of spray drying conditions. Journal of Drug Delivery Science and Technology, 2016. 36, 46-54.

[17] Carvalho, A.G.S., V.M. Silva, and M.D. Hubinger. Microencapsulation by spray drying of emulsified green coffee oil with two-layered membranes. Food Research International, 2014. 61, 236-245.

[18] Ortiz-Jerez, M.J., T. Gulati, A.K. Datta, and C.I. Ochoa-Martínez. Quantitative understanding of Refractance Window ${ }^{\mathrm{TM}}$ drying. Food Bioprod. Process., 2015. 95, 237-253.

[19] Baeghbali, V., M. Niakousari, and A. Farahnaky. Refractance Window drying of pomegranate juice: Quality retention and energy efficiency. LWT - Food Science and Technology, 2016. 66, 34-40.

[20] Artiga-Artigas, M., A. Acevedo-Fani, and O. Martín-Belloso. Effect of sodium alginate incorporation procedure on the physicochemical properties of nanoemulsions. Food Hydrocolloids, 2017. 70, 191-200. 